I Universidade Federal do Rio de Janeiro (UFRJ), Programa de

Pós-Graduação em Sociologia e Antropologia, Rio de Janeiro, RJ, Brasil

elina.pessanha@gmail.com

https://orcid.org/oooo-ooor-8443-I534

Elina Pessanha'

\title{
TEMPO, MOVIMENTO E TEORIA SOCIAL: \\ GABRIEL COHN, UM VOO SOLO \\ A PARTIR DE SÃo PAULO
}

Neste ano de 2020 faz I0o anos que nascia Florestan Fernandes e morria Max Weber.

A máxima de Theodor Adorno "Quanto mais bruto o mundo, mais fina deve ser sua análise", se impõe aqui naturalmente ao apresentar este conjunto de entrevista e textos de e sobre o respeitado e admirado intelectual brasileiro que é Gabriel Cohn. Ela cabe como luva para definir a obra e a postura acadêmica - também política - desse sociólogo crítico à dureza dos efeitos do capitalismo que, sob o véu de uma organização social "moderna", tem marcado os passados, presentes e provavelmente marcará ainda futuros tempos do mundo ocidental.

A entrevista que se segue foi realizada por André Botelho, Antonio Brasil Jr. e por mim, bem antes da brutalidade da crise sanitária, econômica e política que ainda nos assola.

Sua publicação, hoje, se junta às homenagens a dois intelectuais que estão na raiz do pensamento de Gabriel. Há um século, contaminado pela chamada gripe espanhola, falecia Max Weber, avaliador atento das contradições da modernidade e que ainda nos alerta, nestes tempos de cruas opções "de defesa da vida ou retomada da economia", para os impasses entre ética moral e ética política. Há roo anos também nascia Florestan Fernandes, um de nossos maiores pensadores, intelectual militante, formador e influenciador de gerações de cientistas sociais brasileiros ao estilo de "plebeus radicais" comprometidos com o destino de nossa sociedade.

O depoimento que nos deu Gabriel permite, em primeiro lugar, viajar com ele por uma rápida narrativa biográfica, ao sabor de seu humor, de críticas e autocríticas muitas vezes veladas, de seus afetos. Ele destaca o estímulo da 
família em que nasceu e da família que criou com Amélia Cohn, intelectual ativa pela justiça social, e os filhos Sergio, poeta/editor e Clarice, antropóloga, ambos sensíveis e atuantes.

O relato é também revelador da história da geração de cientistas sociais que se seguiu aos precursores, no Brasil, de um campo de saber instigante e polêmico, desde sempre ameaçador aos poderes autoritários. A Florestan Fernandes, referência inquestionável, e a Octavio Ianni especialmente, Gabriel diz dever o aprendizado de pensar de modo independente. Com formação - da graduação ao doutorado - e carreira de professor concentradas na USP, o filho de imigrantes judeus criado no vale do rio Paraíba que se atribui mesmo um modo paulista "caipira" de ser, registra que na universidade foi sempre estimulado ao contato com a literatura acadêmica internacional.

O fato de ler alemão o aproximou de uma produção menos consumida então, e ele se tornaria progressivamente uma referência obrigatória sobre teoria social alemã e particularmente sobre Max Weber. Lembra que foi um dos primeiros professores a oferecer uma disciplina explicitamente de teoria sociológica em sua universidade, e certamente marcou muitos alunos com sua atitude entre séria e um tanto "excêntrica", como ele mesmo diz.

Frente a um Florestan catedrático, que, em nome da coerência de sua formação, deixara claro que não o aceitaria de volta se fosse fazer pós-graduação na Flacso-Chile, o jovem Gabriel optou por ficar em São Paulo. Ficou, mas lançou-se num "voo solo", teórico, que alimentaria para sempre a autonomia e a originalidade de sua reflexão.

Sua extensa obra, que ele também comenta no depoimento, é marcada pela reverência aos grandes clássicos - além de Marx, Weber e Durkheim, ele inclui Simmel - e pela influência inspiradora de autores principalmente de origem alemã (mesmo a respeito de Durkheim ele destaca a condição fronteiriça de sua cidade francesa...). Depois de uma dissertação de mestrado sobre a política do petróleo e a criação da Petrobras, num projeto de Florestan e Fernando Henrique Cardoso para o recém-criado Cesit, ele inicia sua incursão nos temas da comunicação e da indústria cultural que o acompanhariam para sempre.

Entre seus diversos livros, artigos, capítulos e apresentações, afora o crédito reiterado à obra do mestre Florestan Fernandes, são muitos os estudos publicados sobre os alemães: além de Weber e várias vezes comparando-os entre si, Adorno, Horkheimer, Habermas, Simmel e Luhmann. Neste dossiê, aliás, seu texto que aborda os distanciamentos e aproximações de Weber e Adorno é um belo exemplo disso.

Gabriel Cohn defende a atualidade da herança de Frankfurt, revitalizada por conceitos gerados a partir dos existentes e por uma interdisciplinaridade para além do institucional, e compartilha com Luhmann a preocupação com a fragilidade conceitual corrente. Atribui a Simmel e a Adorno, este último o autor de quem se sente mais próximo, a sua sensibilidade para as "diferenças 
finas" durante a análise, e se vale da imagem da "busca da forma fugidia", para reiterar o uso necessário da dialética, que permite apreender o movimento, "o jogo", entre a matéria da vida social e as formas imprevistas que esta assume para se reproduzir no tempo - outra categoria provocadora.

$\mathrm{Na}$ época da entrevista ele se concentrava em terminar mais um livro. Sua sensibilidade sociológica o levava a refletir sobre o mote "os inocentes pagam pelos pecadores", ouvido pela primeira vez na infância e socialmente naturalizado entre nós. Um padrão cultural de fundo, controverso, que o desafia ainda hoje a "surpreender tendências onde estão mais ocultas" e encontrar uma explicação estrutural para o sentido de nossa sociedade tão desigual e injusta. Espero que em breve tenhamos dele, como tivemos de vários grandes intelectuais que o precederam, outra brilhante interpretação do Brasil.

Passando aos artigos que se seguem à entrevista, além de um do próprio Gabriel, já citado, há três de outros autores, que se referem diretamente a sua trajetória ou dialogam com sua obra, ou ainda com suas referências.

O primeiro deles, de Bruna Della Torre, enfrenta a interpretação crítica de Cohn sobre Weber em Crítica e resignação. Ela sugere que Cohn faz uma leitura imanente da obra de Weber, e a expõe muito bem em seus impasses e dualismos - como entre ação e conhecimento, ou racionalidade e irracionalidade. Com a abertura e profundidade de seus ensaios, segundo a autora, Gabriel se credencia não como um mero comentarista, mas como um crítico denso da obra, com uma crítica que "parte de algum lugar, lugar esse próximo da teoria crítica e de Marx".

O texto de Leonardo Octavio Belinelli retoma o processo formativo de Gabriel. A partir de artigos, livros e teses, destaca a marca frankfurtiana que caracteriza sua autonomização intelectual e também a autorreflexão sobre sua tradição intelectual, exercitada ao escrever sobre Florestan Fernandes.

Leopoldo Waizbort nos traz um artigo em que dialoga com Gabriel e o reconhecimento que ele externa a respeito da contribuição teórica de Luhmann. O texto também reconhece o esforço de atualização sociológica feito por Luhmann, além de lançar luz sobre uma vertente menos reconhecida da moderna teoria dos sistemas e seus desdobramentos.

Este número da revista traz também, como registro de pesquisa, o texto em que Horacio González, ex-aluno e eventual parceiro de algumas "excursões" teóricas do professor marcante, expõe o "exercício" de produção conceitual e teórica de Cohn e inclui comentários acerca de dois livros de Gabriel, Crítica e resignação, fundamentos da sociologia de Max Weber (Cohn, 2003, cuja edição original é de 1979) e Weber, Frankfurt: teoria e pensamento social (Cohn, 20I7b), defendendo o interesse e a importância das questões centrais levantadas, e a atualidade das nuanças de oposição e comparação - entre Weber e Gramsci, por exemplo - que aparecem nessas obras. 
Sociologia \& Antropologia Gostaríamos de ouvi-lo sobre seus anos de formação na USP, se possível especialmente sobre o papel da teoria sociológica na sua formação e o lugar que ela ocupava no curso de ciências sociais naqueles anos.

Gabriel Cohn Falar do ambiente propiciado pela formação na USP é sempre um desafio muito bem aceito. Ainda mais quando foi no interior da USP toda a minha formação, graduada e pós, e depois, como professor (quando deixei os mestres para tentar aprender com os estudantes, que se esforçaram ao máximo, porém sem muito sucesso). Se há algo peculiar em minha formação e posteriormente em meu trabalho é que tudo, literalmente tudo, foi feito praticamente sem sair da USP e de São Paulo (bem, não tudo; muitas vezes fui buscar material de estudo na biblioteca da Unicamp, muito boa na época, a ponto de justificar a longa viagem a Campinas). As obras em alemão de acesso mais difícil eu encontrei ou encomendei não em Heidelberg ou Frankfurt, mas na Livraria Alemã, a poucos quarteirões de casa. Isso certamente teve seu efeito nos trabalhos apresentados, em especial no que diz respeito a acesso a bibliografia e fontes. $\mathrm{O}$ contato com pesquisadores de outras paragens certamente é interessante, mas nessas horas sempre me ocorre a resposta de Florestan a colega que dizia "mas como, você está lá e não fala com ele?", ao que ele retorquiu “ora, a obra dele eu conheço, que mais vou querer?" Numa coisa ele era implacável, não abria mão da ideia de que a formação básica deve ser numa específica instituição, para depois enfrentar o mundo bem equipado - o que significava tanto a dimensão estritamente acadêmica quanto a da ação política. Quando fui selecionado por Johan Galtung para fazer pós-graduação na Flacso-Chile ele me comunicou, a seco, no tom imperioso que um catedrático podia se permitir na época: "você pode ir, mas aqui não volta mais". Ele entendia, não sem motivo, que a Flacso, apesar de sua qualidade, era um centro voltado para a arregimentação de jovens promissores em toda a América Latina para retirar-lhes o ranço marxista e lhes propiciar bom treinamento técnico (no que levava ampla vantagem em relação à USP naquela época), e, no conjunto, lhes ministrar formação consoante uma concepção liberal, aberta e arejada, diga-se de passagem (por exemplo, Galtung é figura de proa nos estudos internacionais sobre a paz). Que a Flacso teve muito sucesso nisso é atestado pelo número de figuras brilhantes, em especial de Minas Gerais, um centro poderoso na época com ênfase na ciência política, que deixaram de lado seu radicalismo em benefício de uma formação mais profissional e uma deriva mais "conservadora" no modo de pensar. É como se na USP daquela época o objetivo final fosse criar radicais bem formados, capazes de sustentar suas posições com argumentos bem fundados e, sobretudo, capazes de fazer estudos rigorosos da realidade social que os liberassem de qualquer "achismo", mesmo com o risco de ser "provincianos". O risco de uma visada estreita e até mesquinha não era grande, pois a exigência de contato com a produção internacional existia desde a graduação. Nesse sentido a formação era 
mais "cosmopolita" do que a norte-americana e também a europeia, centradas na produção local. Tinha-se contato com muita coisa (claro que com acesso à bibliografia incomparavelmente mais difícil do que agora), o resto ficava por conta do interesse e da criatividade.

Feitas as contas, todavia, eu sou temerário a ponto de sustentar que aquele modo "caipira" (que literalmente sou, tendo me criado em zona rural paulista no vale do Paraíba) de trabalhar teve efeito mais positivo do que negativo. Era uma maneira um tanto radical de pôr em prática a principal coisa que aprendi com mestres como Florestan Fernandes e Octavio Ianni, o cultivo de um modo independente de pensar. Essa coisa de achar que pensar só com a própria cabeça era suficiente conduziu a incidentes insólitos, como na defesa de minha tese sobre Max Weber. ${ }^{\mathrm{I}} \mathrm{Mal}$ contendo seu espanto (e talvez mal-estar, mas ele era elegante demais para deixar transparecer isso) Raymundo Faoro quis saber por que eu não tinha usado a biografia de Max por sua mulher, Marianne Weber, e recebeu a resposta sumária de que eu não a considerava confiável. Nas mãos de arguidor mal-humorado isso poderia ter-me custado caro.

No entanto, sou grato até hoje pelo poderoso estímulo de mestre respeitados para não fazer concessões no tocante à independência na busca e enfrentamento de problemas. Que tipo de problemas? Não caberia responder sem mais que se tratava de problemas de natureza teórica, como a partir do doutorado pratiquei. Em primeiro lugar porque naquela época o curso de ciências sociais não reservava nicho especial para a teoria. Considerava-se, com razão, que ela já estava presente e manifesta nas obras e no trabalho didático dos mestres, especialmente aqueles com quem eu tinha mais contato, na sociologia. Digo isso sem nem por um momento menosprezar a contribuição dos notáveis professores de política e de antropologia naqueles dias, por mais que na primeira se cultivasse mais a historiografia política, especialmente pela brilhante e algo esquecida Paula Beiguelman, sem tanta atenção à pesquisa e à reflexão contemporânea na área, com Oliveiros Ferreira conseguindo fazer a ponte entre tratadistas seiscentistas e as questões mais atuais e, mais adiante, com Francisco Weffort fazendo seminários sobre o então desconhecido Os donos do poder. ${ }^{2}$ Difícil mesmo era escapar do encanto da antropologia, com a atormentada figura da erudita e inteligentíssima Gioconda Mussolini e com Egon Schaden, com obra citada até hoje e figura notável como professor. Mais tarde a área receberia novos aportes nesse campo com Eunice Durham, mulher tenaz que nunca hesitou em nadar contra a corrente por mais forte e popular que fosse, e com Ruth Cardoso, formadora com sua inteligência suave de gerações de jovens antropólogos.

E a teoria social (ou sociológica em sentido mais restrito) nisso tudo? Ela veio devagar, abrindo caminho no campo dos estudos e pesquisas naquilo que era a principal preocupação da época, a do desenvolvimento. Isso, a ponto de 
um grande mestre esquecido, Luiz Pereira, se entusiasmar tanto, que praticamente não aceitava proposta de trabalho que não contivesse referência explícita ao tema, chegando a recomendar (sem sucesso) isso no programa que fiz na época para a recém-criada disciplina de análise sociológica da comunicação. Com a criação, por Florestan Fernandes e Fernando Henrique Cardoso, do centro de pesquisa sobre problemas da industrialização e do trabalho junto à sociologia, o Cesit, eu e vários colegas de minha geração encontramos um nicho para tratar do tema em termos acadêmicos. Foi disso que resultou meu mestrado, sobre a política do petróleo e a criação da Petrobras, que acabou sendo publicada em livro recentemente reeditado pela editora da Unifesp. ${ }^{3}$ Depois disso, seguiu-se o longo mergulho na área teórica.

É importante lembrar que, embora não tivesse nicho institucional definido, a teoria social estava no ar, pertencia ao ambiente da sociologia na época. Um pequeno incidente é significativo. Caminhava eu pela célebre rua Maria Antônia rumo à Faculdade, com um livro - de teoria, claro - debaixo do braço quando encontro Florestan Fernandes. Ele, como sempre fazia nesses casos, quis saber o que eu estava lendo. Mostrei, era um simpósio de teoria sociológica organizado por Llewellyn Gross. ${ }^{4}$ Ora, comentou ele após se inteirar do conteúdo, isso aí eu já dizia há anos. O pior é que no essencial era verdade, mas, para chegar lá, era preciso atravessar a densa selva da escrita do mestre e decifrar seus achados e intuições. Uma combinação ótima: um mestre que te convida a ter cabeça própria e ao mesmo tempo fornece abundante material, não evidente e sim para ser decifrado. (Agora, quando escrevo isto, percebo que estou entre os primeiros a ministrar uma disciplina específica de teoria sociológica na USP.)

S.A. Sua esposa, Amélia, é cientista social, sua filha, Clarice, é antropóloga, e seu filho, Sergio, é um editor importante; conte-nos um pouco como é formar uma família de intelectuais.

G.C. Realmente, há uma espécie de overdose de professores e intelectuais na família, e isso vai longe, pelo ramo materno (meus pais não tinham formação universitária). Eu me beneficiei muito da convivência com essa singular equipe formada por Amélia, Clarice e Sergio. Pelo modo como vêm conduzindo a vida, eles demonstraram a este incorrigível teórico como é possível fazer trabalho de valor em mais de um registro. Amélia, ao associar à sua atividade acadêmica na USP a participação ativa na formulação e implementação de política pública (Bolsa Família) e ao dedicar-se à pesquisa e à direção de importante entidade da sociedade civil, o Centro de Estudos de Cultura Contemporânea - Cedec; Clarice, ao associar à sua condição de pesquisadora e docente em antropologia na UFSCar a militância ativa na defesa dos direitos dos povos indígenas, incluindo nisso a resistência a essa estranha entidade que é a usina hidroelé- 
trica Belo Monte; Sergio, ao associar à sua atividade como poeta a condição de fundador de importante pequena editora, a Azougue. Se isso não for estímulo para me esforçar no meu trabalho, nenhum regulamento administrativo será.

S.A. Nos fale a respeito de sua experiência como professor, sua relação com orientandos e os jovens alunos. E também sobre o papel dos estudantes como provocadores de novas experiências e reflexões no campo do magistério e da pesquisa.

G.C. Não sei se gostaria de ser meu aluno na graduação. Ou talvez gostasse especialmente. Afinal, havia gostado das aulas do erudito Ruy Coelho (de quem Gioconda dizia que ele deveria ficar no saguão da faculdade, para atender a qualquer pessoa que tivesse qualquer dúvida sobre qualquer assunto). Elas começavam bem comportadas, quase disciplinadas, para logo entrar em deriva numa corrente de temas. De certo modo as gerações de estudantes com quem tive contato se dividiam entre esses dois polos. Certamente nunca fui unanimidade, nem a favor nem contra. Devo muito aos estudantes que gostavam do meu modo um tanto excêntrico de dar aulas, nas quais a conclusão tendia a ficar para depois. (Eu poderia usar a frase com que Fernando Henrique Cardoso, em aulas de primeiro ano, respondia à inevitável questão "e Marx, professor?". A resposta invariável era "eu chego lá" - e nunca chegava. Mas chegava a muita coisa importante, em seus seminários sobre Brasil e América Latina, sobre questões de desenvolvimento, claro, que equilibravam as exposições introdutórias inteiramente ortodoxas. Ele ainda não havia chegado ao tema da dependência, que só se manifestaria a partir de i965). Fernando Henrique, por sinal, é responsável por uma prática que se revelaria danosa para a formação em sociologia na USP. Fez isso ao incluir em seu livro sobre capitalismo e escravidão um prefácio teórico-metodológico que era sobretudo um manifesto de independência em relação a Florestan, com quem havia feito o doutorado que era base do livro. Era como que a proclamação de formação de novo grupo científico, com fundamentos da pesquisa que pouco deviam aos precedentes. Mais tarde essa independência ganharia corpo no Cebrap. Nesses termos aquele acréscimo ao livro fazia sentido; o diabo é que depois virou obrigação em qualquer tese o famoso "nariz de cera" teórico, que no mais das vezes não era teoria nem manifesto. Muita gente passou a ver a teoria como mero ingrediente de texto anódino ou como anódina ela própria.

Naquela época a quatrocentona USP vinha se abrindo para um público mais diferenciado, que incluía descendentes de imigrantes, como eu, ao lado de filhos ou sobrinhos de renomados intelectuais. Como professor, cheguei a encontrar numa mesma sala André Singer, Marcelo Coelho e Marcos Nobre, para só falar de alguns. No entanto, a USP parava muito rápido na escala social, e a prova evidente disso era a dificuldade para encontrar colegas negros, em- 
bora cada vez mais se notasse a presença de jovens de bairros distantes. Mas era uma escola radicalmente diferente da atual, para o bem (pequena, descontraída, alta qualidade) e para o mal (ainda com carga elitista).

S.A. Uma pergunta incontornável quanto a sua trajetória intelectual é sobre sua relação com a teoria social alemã; poderia nos contar um pouco a esse respeito? Como começou e que reação provocou entre seus colegas?

G.C. Naquela época a teoria social alemã ainda não tinha o lugar de destaque que viria a ocupar a partir do período final do século passado. Ainda não havia então a política oficial alemã de se fazer valer na academia latino-americana (e no mundo todo, suponho), que se revelaria muito bem sucedida. Exatamente por isso eu tinha uma vantagem, a de ler alemão. O que só poderia me levar a concentrar esforços na teoria social alemã, sem me descuidar demais do resto, porém. Foi por aí que acabei me dedicando ao estudo do pensamento de Max Weber, a ponto de se espalhar que o único tema que me interessava era isso e que eu era portentosa autoridade no assunto. Nenhuma das duas coisas tinha fundamento, claro. Na época da minha graduação quase ninguém, ou mesmo ninguém se dedicava à produção alemã como tal, descontando os clássicos. Foi só na fase final de minha graduação, em I962, que o principal responsável por se colocar a produção alemã no mapa, Jürgen Habermas, publicou seu clássico sobre a esfera pública. Sem efeito imediato, contudo, pelo menos em São Paulo, enquanto no Rio o grupo próximo à revista Tempo Brasileiro (que com alguma maldade poderia ser chamada de Tempo Alemão) se adiantava. Como de costume, aliás, pois o Rio sempre foi mais ágil na atenção a movimentos contemporâneos, enquanto São Paulo se dedicava a examinar a fundo algumas poucas coisas. Como lembraria Isaiah Berlin, a raposa conhece muitas coisas (e se dispersa), e o porco-espinho só conhece uma (e se aprofunda). Para o bem e para o mal, tínhamos na USP o protótipo do porco-espinho, Florestan, enquanto o Rio produzia figuras mais desenvoltas, como Guerreiro Ramos ou mesmo Hélio Jaguaribe (uma figura marcial e outra solar, nada mau).

S.A. Gostaríamos que nos falasse sobre os clássicos das ciências sociais. O senhor é um autor muito atento a eles. É o senhor mesmo autor de um clássico das ciências sociais brasileiras focalizando Max Weber ${ }^{5}$ e, além disso, tem outro livro dedicado justamente ao problema e que também vem sendo lido há gerações; ${ }^{6}$ por fim, tem feito análises preciosas e muito criativas recolocando alguns clássicos em discussão, inclusive Durkheim. Qual a importância dos clássicos na teoria e nas ciências sociais em geral?

G.C. Não tenho dúvida sobre a importância do estudo dos clássicos. No caso da Sociologia temos o quarteto Marx, Weber, Durkheim e Simmel (que se juntou 
bem depois aos célebres "três porquinhos" e que na minha época mal existia). Estranho, três deles alemães e o quarto oriundo de área limítrofe França-Alemanha. Será que se repete na sociologia - não na ciência política, que trabalha em outro registro temporal e de relevo no pensamento, começando nada menos do que com Aristóteles - algo semelhante à grande música de concerto desde o século XIX? Nesse caso, revela-se bem salutar a virada anglo-norte-americana a partir da segunda etapa do século passado, sem prejuízo de que então muitos da nova geração de norte-americanos, até Talcott Parsons, tivessem ido estudar ... na Alemanha. Não raro os clássicos são enervantes, quando dão a impressão de já ter dito tudo, à maneira deles. Mas não se pode esquecer de que eles tinham uma avenida pela frente, enquanto os pósteros encontram vias congestionadas.

O problema na minha época na USP era que o debate contemporâneo tendia a ser deixado de lado por efeito de uma dedicação, quando não reiteração, dos grandes autores e das grandes obras. O resultado disso não envolvia automaticamente formação melhor, suspeito que em alguns casos até tenha deixado impaciente mais do que uma estudante. (Uma, sim, pois as mulheres formavam pouco menos da metade da classe típica). Para evitar isso, que conspira para desestimular nos estudantes a reflexão de longo prazo e não apenas a decisão técnica pontual (sempre insisti com meus alunos que a questão sobre uma aula ser boa - isso é, relevante - não se resolve no imediato, e sim no longo prazo, quando ela volta à memória ao se enfrentar problema de pesquisa), não há como subestimar o contato sistemático com as grandes obras. O que em minha época ainda não estava claro é que arrumar os clássicos em fileira para melhor examiná-los não é a solução mais indicada. Só muito depois tomaria corpo a ideia de que a ênfase central deveria incidir mais sobre problemas e os quadros conceituais aptos ao seu estudo, com o que se forneceria âncora firme para tratar dos grandes autores (e não de meros epígonos, como diria Max Weber).

S.A. Ainda com relação aos clássicos, mas desta feita, em relação a um movimento teórico que enlaça gerações diferentes de teóricos e que permite pensar desenvolvimentos plurais da teoria, e não meros aperfeiçoamentos lineares, lembramos seu trabalho sobre Simmel e Luhmann.7 Está correto dizer que se desenha ali uma espécie de paradigma teórico, o das diferenças finas, que permite repensar os processos de autonomização para além da constituição de campos estruturados, ao modo de Pierre Bourdieu? Isto é, que permite antes investigar a circulação e a comunicação entre diferentes formas de interação social?

G.C. A questão da sensibilidade para diferenças finas no lugar do pensamento em blocos sempre me fascinou. No entanto, só ganhou forma a partir daquele 
artigo, certamente sob o impulso da admirável figura de Simmel. Tendo sido colocada na pauta, só fez crescer e se aprofundar. E aí entra, do ponto de vista teórico, a presença desta outra figura, pós-simmeliana por assim dizer, Adorno, o autor de quem, apesar de todas as dificuldades, eu me sinto mais próximo. Como hipersensível que era, ele ofereceu elementos para o passo seguinte em toda a sua obra, a começar por Minima moralia. Consiste ele na inspiração para um mote no meu entender muito importante para o cultivo da sociologia no período atual e, com forte razão, no futuro próximo. Venho repetindo esse mote em todas as oportunidades, porque realmente me parece sério. Seu teor é quanto mais bruto o mundo, mais fina deve ser sua análise. Ao contrário do que se poderia esperar, a brutalidade do mundo só faz aumentar. E não adianta responder a isso no estilo ianque, de bater de frente para ver quem sairá com o nariz sangrando. É preciso ser leve, infinitamente móvel (mobilidade é uma palavra-chave nesse contexto), ágil o bastante para enfrentar um mundo que conseguiu, pela primeira vez na história, associar intimamente a leveza mais diáfana na organização e no controle dos grandes processos econômicos com a esmagadora dureza das novas formas de acumulação original de capital.

Aqui, sim, temos um imenso problema teórico. Para enfrentá-lo teremos sem dúvida que mobilizar os grandes clássicos e, a partir deles, esmiuçar o que se tem feito e o que se está fazendo em todos os desvãos da pesquisa e da reflexão nas ciências sociais. Pois a partir desse ponto os limites disciplinares deverão ser substituídos por modos de entrelaçamento de conceitos encontrados onde menos se espera. Nada de "interdisciplinaridade" institucional, e sim cultivo da atenção, da sensibilidade alerta, da capacidade de ver o maior imbricado no menor e depois fazer o caminho de volta. Nesse trabalho valerá a pena rever propostas aparentemente obsoletas, mas sujeitas a revisões e reinterpretações, sempre contra a tendência em nossa área a agir como se tudo começasse de novo a cada dez anos. Estou seguro de que preciosidades estão escondidas no velho/novo baú. Nunca tive coragem para formalizar isso, mas penso que um debate, talvez na Anpocs, sobre os "grandes esquecidos" faria sentido, tanto internacionalmente quanto no Brasil.

A exigência é de concentrar atenção no aparentemente insignificante, para nisso angariar pistas para examinar o que está às costas dos formidáveis (no sentido pleno, de admirável e amedrontador) fenômenos em que se exibe o mundo contemporâneo. É que, tanto quanto consigo ver, está mesmo na hora de recuperar algo maldito, a dialética, esse procedimento enigmático que permite fazer o mais difícil. Trata-se de surpreender em movimento o jogo em que se entrelaçam de modo conflitivo, porém necessário para a persistência dos dois lados, a matéria da vida social e as formas que ela tem que assumir para se reproduzir no tempo (este último termo é mais importante do que nunca, e requer mais atenção do que lhe vem sendo dada). Em dimensões fundamentais o mundo ganha caráter cada vez mais fantasmagórico, um jogo de 
formas que rapidamente se furtam ao olhar (lembram os "deuses instantâneos" de que falavam os antigos antropólogos; Cassirer narra isso). O essencial é que elas se tornam cada vez mais ocultas enquanto a parte visível só faz crescer. O argumento, enfim, é que pela recuperação e o aggiornamento da dialética (como Adorno tentou fazer) se possa fazer o mais difícil, que é captar a dinâmica do mundo a partir das formas que a sustentam, naquilo que eu chamaria de pesquisa da forma fugidia. No entanto, praticamente todo mundo abandonou esse campo de cogitações, incluindo nisso os novos (pós-Habermas) integrantes da teoria crítica. Claro que há forte recuperação de Marx, mas há muito a fazer para isso irrigar as ciências sociais.

S.A. Em trabalhos recentes, o senhor vem propondo aproximações ou, melhor, "irritações" - para usarmos um termo caro à teoria dos sistemas sociais - entre o legado clássico da sociologia e a obra de Luhmann. Além do já citado artigo sobre Simmel e Luhmann, lembramos a série de palestras intitulada Adeus, Weber, em que uma reinterpretação bastante provocativa de Weber é feita a partir das questões postas pelo autor de A sociedade da sociedade. ${ }^{8}$ Esse nos parece um ponto bem original, pois Luhmann explicitamente se propõe a recriar a teoria sociológica conferindo um lugar bastante subalterno aos clássicos da disciplina. O senhor poderia comentar um pouco esse ponto?

G.C. Luhmann tem algo de moleque. Com sua curiosidade insaciável ele se mete em tudo e nada deixa em pé. Ele conseguiu associar a subversão generalizada à conservação irrestrita do mundo como sistema. Talvez vá por aí a extraordinária capacidade de seu esquema analítico para traçar um quadro altamente plausível da organização (sistema) e da dinâmica (comunicação) deste mundo complexo. A proposta luhmanniana não se restringe a isso, mas como descrição com alto nível de abstração (adequada a um mundo com caráter abstrato) daquilo que nele ocorre ela não tem par. É sempre dolorosa a comparação de Luhmann com seu arquiadversário Habermas. Enquanto este, após mais de seis décadas de combate cotidiano em todos os níveis por um mundo minimamente civilizado, corre o risco de ver esmorecer o seu brilho, o de Luhmann só aumenta. Odeio dizer isso, mas a compreensão do mundo contemporâneo passa por Luhmann. Para ele os grandes autores clássicos contribuem muito pouco para a construção da teoria social que defende, por uma razão devastadoramente simples. Insuficiência conceitual, esse é problema para ele. Não poderia haver posição mais teórica do que essa, solidamente instalada no plano conceitual. E nesse plano Luhmann encontra nos clássicos a imprecisão conceitual generalizada, o que o deixa comprometido unicamente com os conceitos que ele mesmo constrói, numa posição que não admite compromisso. Expresso em alternativa radical, ou ele é um teórico solitário que dispensa os clássicos sem colocar um quadro conceitual válido em seu lugar, ou é, sim, o 
grande teórico contemporâneo, o inventor de um paradigma ao qual todos terão que aderir, cedo ou tarde. Com a profusão de conceitos e propostas de paradigmas que povoam a teoria contemporânea fica difícil encontrar apoio para qualquer ponta.

S.A. Para nossa felicidade e dos leitores brasileiros o senhor está reunindo e revendo alguns dos seus textos esparsos em Weber, Frankfurt. ${ }^{9}$ Como está sendo a experiência? Qual o lugar da teoria alemã nas ciências sociais hoje?

G.C. É uma aventura estimulante rever antigos textos e enfrentar o desafio de escrever um novo sobre determinado tema, em geral resultado de compromisso criado pelo próprio autor. No segundo volume o antigo compromisso era com escrever algo a respeito da relação entre Weber e Adorno, a dupla que acabou pautando minha trajetória no campo da teoria. No primeiro, havia sido escrever sobre Marx, desafio pesado, que acabei enfrentando como pude. O grande desafio, contudo, está no terceiro volume, que há muito está preparado, à espera de artigo que representa o problema máximo para mim, a fera temível que pode dar o salto a qualquer momento.

Deixem-me explicar. Esse volume reúne peças várias, sobre questões e autores brasileiros. Falta só a última, e é isso que está atrasando a publicação e de certo modo contribuiu para o atraso do segundo volume, por puro medo de me ver enfrentando a fera sem desculpa alguma. Claro que a fera só existe para mim, talvez para outros seja até bem mansa. No que diz respeito a mim ela só fez crescer e ganhar força e ferocidade ao longo de muitos decênios. Sua origem remota está em episódio da infância, quando professora, ao ser indagada por ter aplicado castigo a todos quando só havia um responsável, respondeu com inteira naturalidade, "os inocentes pagam pelos pecadores". Isso ocorreu há mais de 70 anos, mas ainda ressoa na memória e inspira em mim o desejo, mais do que isso, a obrigação de pôr a serviço de seu exame os recursos que minha condição de perguntador profissional sobre essas coisas me propicia. A questão, afinal, é como é possível tal coisa? Como tal enormidade pode ser proferida sem despertar em (quase) ninguém espanto e revolta? Nos termos que eu aprenderia passado algum tempo, que tipo de sociedade é essa, que engendra, legitima e incentiva essa concepção de vida? O problema consiste em encontrar, para além da exploração de sintomas como o autoritarismo, o passado escravista e outros assim, algum padrão mais fundo, em que se possa ancorar uma explicação estrutural e não meramente circunstancial dessa questão, ou complexo de questões. Assim como no meu verso favorito de Garcia Lorca, eu sei que nunca chegarei a Córdoba. Mas me sentirei mal se não tiver, pelo menos, posto o pé na estrada. E nesse ponto minha ligação com a reflexão social alemã e, junto, minha formação na USP mostrarão se valeu a pena. 
S.A. Também quanto ao lugar da teoria alemã, lembramos que o senhor publicou vários trabalhos sobre os meios de comunicação de massa, incluindo a organização de uma coletânea que é referência para esse campo de estudos. ${ }^{10}$ Hoje, diante da revolução comunicacional e das consequências políticas implicadas pela Web 2.0, muitos cientistas sociais se veem tentados a abandonar a herança teórica de Frankfurt. Não seria, pelo contrário, o momento de voltar a ela?

G.C. Certamente eu penso que esse é um momento para pôr a herança de Frankfurt a serviço do exame das condições presentes dos processos de comunicação. Aquilo que Adorno chamava de indústria cultural continua firme e forte, só que com outra fisionomia e outros padrões de funcionamento. O que importa, no entanto, não é só mostrar que ideias que já se expressam na teoria tal como formulada originalmente ainda são válidas, e sim que o esquema conceitual da teoria crítica pode, por sua vez, gerar conceitos a partir dos anteriores e devidamente adequados à nova configuração do objeto de análise, ou seja, a formação social capitalista. Algo como uma nova versão da ideia adorniana da regressão da capacidade de audição musical para estudar as novas formas de difusão de conteúdos sonoros, ou uma revisão da ideia de participação política na forma de esquemas fechados tipo ticket, ampliando-a para outras dimensões da sociedade, com base na concepção de que tendências particulares encontradas numa fase vão no sentido de se generalizar pelo conjunto da sociedade na sequência. Outro aspecto da questão é de especial interesse nas condições contemporâneas das ciências sociais. Trata-se de retomar e aprofundar a orientação primeira da teoria crítica, no sentido de um trabalho teórico voltado para a pesquisa com forte caráter multidisciplinar, tal como preconizado na construção da TC por Horkheimer. Algo como uma retomada da junção procurada naquela época entre sociologia e psicanálise, alimentada por fontes tão diversas como a análise política e a teoria literária, eventualmente a linguística.

Recebida em 27/7/2020 | Aprovada em Io/8/2020

Elina Pessanha é professora titular aposentada da UFRJ, membro permanente do Programa de Pós-Graduação em Sociologia e Antropologia da mesma universidade e pesquisadora do CNPq. É autora de Operários navais - trabalho, sindicalismo e política na indústria naval do Rio de Janeiro e organizadora, com Villas Bôas, Morel e Leite Lopes, de Evaristo de Moraes Filho - Ioo anos de vida contribuição à sociologia e ao direito do trabalho. 


\section{NOTAS}

I Essa tese depois foi publicada em livro (Cohn, 2003).

2 Trata-se do livro de Raymundo Faoro (I958).

3 Ver Cohn (2017a).

4 Ver Gross (I959).

5 Ver nota 3.

6 Ver Cohn (2009).

7 Ver Cohn (1998).

8 O conjunto das aulas está disponível no canal do YouTube da UnivespTV:<https://www.youtube.com/watch? v= LaFaoERNGs $>$. Acesso em Io ago. 2020.

9 Gabriel Cohn se encontra no momento finalizando mais dois volumes de Weber, Frankfurt; o primeiro saiu em 2017 pela Editora Azougue (Rio de Janeiro).

Io Ver Cohn (I97I).

\section{REFERÊNCIAS BIBLIOGRÁFICAS}

Cohn, Gabriel. (2017a). Petróleo e nacionalismo. São Paulo: Unifesp.

Cohn, Gabriel. (20I7b). Weber, Frankfurt: teoria e pensamento social. Rio de Janeiro: Azougue.

Cohn, Gabriel. (2009). Sociologia - para ler os clássicos. Rio de Janeiro: Beco do Azougue.

Cohn, Gabriel. (2003). Crítica e resignação: Max Weber e a teoria social. São Paulo: Martins Fontes.

Cohn, Gabriel. (1998). As diferenças finas: de Simmel a Luhmann. Revista Brasileira de Ciências Sociais, 13/38. Disponível em: <https://doi.org/IO.I590/SoI02-6909I998000 300003>. Acesso em Io ago. 2020.

Cohn, Gabriel (org.). (I97I). Comunicação e indústria cultural. São Paulo: Companhia Editora Nacional.

Faoro, Raymundo. (I958). Os donos do poder: formação do patronato político brasileiro. Porto Alegre: Editora Globo.

Gross, Llewellyn. (I959). Symposium on sociological theory. New York : Harper \& Row. 
Palavras-chave

Teoria social; teoria crítica;

Gabriel Cohn.
TEMPO, MOVIMENTO E TEORIA SOCIAL: GABRIEL COHN, UM VOO SOLO A PARTIR DE SÃO PAULO Resumo

A presente entrevista com o sociólogo paulista Gabriel Cohn, foi realizada em 20 I 9 por André Botelho, Antonio Brasil Jr. e Elina Pessanha, e inclui breves notas biográficas e o registro de sua experiência como estudante e depois professor da Universidade de São Paulo. Provocado pelos entrevistadores, Gabriel fala sobre a importância dos autores clássicos, a influência da teoria social alemã, e os desafios teóricos a enfrentar para produzir uma análise 'fina' da sociedade.

TIME, MOVEMENT AND SOCIAL THEORY: GABRIEL COHN, A SOLO FLIGHT FROM SÃO PAULO

\section{Abstract}

Keywords Social theory; critical theory; Gabriel Cohn.
This interview with the São Paulo sociologist Gabriel Cohn was conducted in 2019 by André Botelho, Antonio Brasil Jr. and Elina Pessanha, and includes short biographical notes and a record of his experience as a student and later professor at the University of São Paulo. Prompted by the interviewers, Gabriel speaks about the importance of the classic authors, the influence of German social theory, and the theoretical challenges faced in producing a 'finegrained' analysis of society. 